\title{
O ENSINO E O APRENDIZADO DO INGLÊS COMO LÍNGUA ESTRANGEIRA EM UMA ESCOLA BILÍNGUE PARA SURDOS: REFLEXÕES SOBRE A PRÁTICA PEDAGÓGICA
}

\author{
TEACHING AND LEARNING ENGLISH AS A FOREIGN LANGUAGE IN A \\ BILINGUAL SCHOOL FOR THE DEAF: REFLECTIONS ON \\ PEDAGOGICAL PRACTICE
}

\section{LA ENSEÑANZA Y EL APRENDIZAJE DE INGLÉS COMO LENGUA EXTRANJERA EN UNA ESCUELA BILÍNGÜE PARA SORDOS: REFLEXIONES SOBRE LA PRÁCTICA PEDAGÓGICA}

\author{
Edvanilda Antônia Borges * \\ Layane Rodrigues de Lima **
}

\begin{abstract}
Resumo
Este artigo tem como objetivo relatar facilidades e dificuldades próprias ao processo de ensino e de aprendizagem do inglês como LE por alunos surdos em uma escola bilíngue, localizada em Brasília-DF. A base teórica se pauta nas discussões sobre o sujeito surdo, sua língua e sua cultura, bem como sobre o processo de ensino e de aprendizagem. Foram realizadas observações de aulas, entrevistas e aplicados questionários a quatro estudantes surdas e a duas professoras de inglês da escola observada. Os dados indicam a necessidade de se utilizar métodos de ensino que contemplem as especificidades linguísticas e culturais dos surdos, especialmente no que se refere ao uso da Língua Brasileira de Sinais nesse processo.
\end{abstract}

Palavras-chave: Escola Bilíngue. Ensino/Aprendizagem. Inglês. Surdos.

\section{Introdução}

A importância do aprendizado de línguas estrangeiras, tanto para fins profissionais e educacionais como na interação entre pessoas é um fato indiscutível no mundo atual, o que aumenta a relevância e a necessidade do aprendizado do inglês

\footnotetext{
* Especialista em Linguística das Línguas de Sinais pela Universidade Fedderal de Goiás - UFG. Graduação em Letras: Libras pela UFG. Professora do Centro de Capacitação dos profissionais da Educação eAtendimento às Pessoas com Surdez (CAS/Goiânia). Email: edvanildaalves @ hotmail.com

** Doutoranda em Linguística pela Universidade de Brasíli - UnB. Mestrado em Linguística pela UnB. Professora de Linguística e de Língua Portuguesa do Departamento de Libras e Tradução da Faculdade de Letras da Universidadde Federal de Goiás, UFG. E-mail: layanel@ gmail.com
} 
como Língua Estrangeira (LE). Este artigo apresenta aspectos do processo de ensino e do aprendizado do Inglês por estudantes surdos de uma escola bilíngue localizada no Distrito Federal.

Baseando-nos em estudos teóricos sobre o sujeito surdo, sua língua e cultura (QUADROS, 1997; STROBEL, 2008) e sobre o processo de ensino do inglês por surdos (SILVA, 2005; MACHADO, 2008), o objetivo é explicitar alguns aspectos desse processo. Para isso, evidenciamos os seguintes pontos: (a) a fluência dos professores de inglês na Libras e o conhecimento sobre a cultura surda; (b) as metodologias de ensino empregadas pelos professores de inglês no ensino a alunos surdos; e (c) o relato de estudantes sobre a experiência deles no aprendizado de uma LE em uma escola bilíngue.

\section{Aprendizagem do inglês como língua estrangeira pelo surdo}

A comunicação humana é um processo natural e ocorre por meio das diferentes línguas usadas em todo mundo, sejam elas orais ou sinalizadas. As línguas de sinais, por sua vez, são usadas pelos surdos. Os surdos utilizam a comunicação espaço-visual, visto que possuem a perda parcial ou total da audição. Sendo assim, a grande maioria dos surdos desenvolve a língua de sinais no contato com seus pares, nas diversas comunidades surdas espalhadas ao redor do mundo.

A língua de sinais pode ser adquirida naturalmente pelos surdos quando expostos a ela e o seu processo de aquisição é análogo ao de crianças ouvintes (cf. QUADROS, 1997). Isso é comprovado em pesquisas iniciadas a partir da década de 1960 pelo norte-americano Willian Stokoe (1960) com a Língua de Sinais Americana (ASL). No Brasil, pesquisas com a Língua Brasileira de Sinais (Libras) foram desenvolvidas por Lucinda Ferreira Brito (2010 [1995]), Ronice Quadros (1997), Tanya Felipe (2007), Ana Regina e Souza Campello (2008) e Shirley Vilhalva (2009), dentre outros, fortaleceram o reconhecimento das línguas de sinais como línguas naturais. Em 24 de abril de 2002, no Brasil, foi promulgada a Lei $n^{\circ} 10.436$, que dispõe sobre a Libras:

Art. $1^{\circ}$ É reconhecida como meio legal de comunicação e expressão a Língua Brasileira de Sinais - Libras e outros recursos de expressão a ela associados. Parágrafo único. Entende-se como Língua Brasileira de Sinais - Libras a forma de comunicação e expressão, em que o sistema linguístico de natureza visual-motora, com estrutura gramatical

própria, constitui um sistema linguístico de transmissão de ideias e Revista Sinalizar, Goiânia, v. 3, n. 2, p. 68-86, jul. / dez. 2018. 
fatos, oriundos de comunidades de pessoas surdas do Brasil (BRASIL, 2002).

No Brasil, há outras línguas de sinais além da Libras, empregadas por comunidades indígenas, como, por exemplo, a língua Urubur-Kaapor e as línguas indígenas de sinais utilizadas em comunidades do estado de Mato Grosso do Sul, como comprovam as pesquisas de Lucinda Ferreira Brito (2010 [1995]) e de Shirley Vilhalva (2009).

Desse modo, o surdo tem garantido o seu direito à inclusão com o uso da Libras nas escolas brasileiras, seja através do profissional intérprete ou com o professor. Os surdos usam como segunda língua (L2) a língua portuguesa, em sua modalidade escrita, e aprendem o inglês como língua estrangeira (LE). Esta situação linguística e educacional está disposta na Lei $n^{\circ} 10.436$ (BRASIL, 2002) e no Decreto $n^{\circ} 5.626$ (BRASIL, 2005), que versa sobre a Libras como disciplinar curricular e do ensino do português como L2 para surdos.

Desse modo, o surdo tem garantido o seu direito à inclusão com o uso da Libras nas escolas brasileiras, seja através do profissional intérprete ou com o professor. Os surdos usam como segunda língua (L2) a língua portuguesa, em sua modalidade escrita, e aprendem o inglês como língua estrangeira (LE). Esta situação linguística e educacional está disposta na Lei $n^{\circ} 10.436$ (BRASIL, 2002) e no Decreto $\mathrm{n}^{\circ} 5.626$ (BRASIL, 2005), que versa sobre a Libras como disciplinar curricular e do ensino do português como L2 para surdos. Sabe-se que a aprendizagem do inglês como LE é um direito de todo cidadão, expresso na Lei de Diretrizes e Bases da Educação Nacional (LDB/Lei no 9.394 de 1996) (BRASIL, 1996). Segundo Silva (2005, p. 66), “é inegável a importância da língua inglesa no mundo atual devido à abertura nos âmbitos comercial, cultural, científico, político e até mesmo turístico, em que ela é a ferramenta que permite que as trocas e/ou relações aconteçam”. Porém, a situação linguística atual dos estudantes surdos no aprendizado do inglês como LE é complexa, como salienta Silva (2005, p. 70):

Hoje a sala de aula de inglês na escola inclusiva pode ser comparada a um delta linguístico composto pelo inglês como língua-alvo, língua essa que o professor deve dominar, o português como língua majoritária na sala de aula e compartilhada pelo professor, alunos ouvintes e o intérprete, e a 
LIBRAS como língua minoritária e conhecida pelos alunos surdos e o intérprete. Três grandes "rios" são responsáveis pela formação deste delta: a inclusão do surdo no ensino regular, a obrigatoriedade do ensino de uma língua estrangeira no ensino público e o fato do professor não saber LIBRAS.

Silva (op. cit.) diz que, em um primeiro momento, a sala de aula parece estar em conformidade com os preceitos da inclusão, mas, quando vista mais de perto, percebe-se que o seu contexto é totalmente contrário ao que se propõe como aula de inglês como LE. Essa situação pode ser ilustrada com o fato de que muitos professores colocam seus alunos em contato com os sons da língua inglesa, ao trazerem músicas, por exemplo, entretanto, para o aluno surdo essa atividade é inútil e até mesmo constrangedora, pois, muitas vezes, o próprio intérprete não sabe inglês. Dessa forma, o aluno surdo é colocado em uma situação de exclusão:

\footnotetext{
Como o professor não fala em inglês e não há nenhuma atividade voltada para o seu uso, os alunos ouvintes e surdos têm uma aula onde basicamente copiam textos e respondem exercícios de gramática que serão corrigidos. Fica muito claro que nesse contexto, onde se têm duas situações distintas, não há como trabalhar com o mesmo método nem com métodos diferentes ao mesmo tempo (SILVA, 2005, p. 70).
}

O ideal seria que as aulas de inglês como LE, no processo de aprendizagem dos surdos, fossem dadas em salas exclusivas, ou seja, em classes separadas. Silva (2005, p. 82) observa que, da mesma forma que são montados, em salas próprias, laboratórios de química, física e computação, também deveria ser valorizado "o espaço reservado para o ensino de língua inglesa para surdos”.

Como os estudantes surdos necessitam de pistas visuais e também em Libras. Assim, é essencial o uso da língua de sinais no processo de ensino/aprendizagem de línguas. O aprendizado de inglês como LE é mais complicado no caso do surdo, por ser baseado no português, "uma língua na qual se supõe já exista um nível cognitivo desenvolvido, mas que ele ainda está aprendendo, melhor dizendo, que ele está tentando desestrangeirizar" (SILVA, 2005, p. 72).

Para Almeida Filho (1998, p. 12 apud SILVA, 2005, p. 72), uma língua só é estranha a princípio, mas que deve se "desestrangeirizar ao longo do tempo de que se dispõe para aprendê-la”. Desse modo, quando se apresenta o português como um meio facilitador no processo de ensino do inglês como LE para o estudante surdo, na verdade 
"acaba-se por dificultar ainda mais a sua aprendizagem, uma vez que ele deve desestrangeirizar duas línguas ao mesmo tempo" (SILVA, op. cit.).

Além disso, Machado (2008, p. 84) observa um problema bastante comum no processo de ensino e de aprendizagem de línguas pelos surdos: “A aprendizagem tardia de uma língua, como é o caso de muitos surdos que aprendem a LIBRAS na adolescência ou na fase adulta, não lhes possibilita, em muitos casos, a reversão total desse quadro". Nesse sentido, Lopes (1997, p. 106 apud MACHADO, 2008, p. 79) afirma que:

(...) esta dinâmica abala uma concepção, tão presente nas escolas, de que a dificuldade de aprendizagem é algo permanente em determinados alunos ("os fracos") e ausente em outros ("os fortes"). A explicação para as dificuldades gira, normalmente, em torno de características individuais ou sociais dos alunos, fazendo com que a escola não se sinta nem responsável, nem impotente diante do que costuma chamar fracasso dos estudantes.

Victor (2010 p. 32) observa que o método avaliativo para alunos surdos deve buscar a superação das dificuldades no processo de ensino e de aprendizagem. Para isso, a autora explica que o professor preocupado com esse processo pode influenciar o aprendizado de forma positiva ou negativa.

A maioria dos professores em atuação, durante a sua formação profissional, não fizeram cursos de Libras. Porém, alguns professores desejam buscar aprender a língua de sinais e a cultura dos surdos para compreender o processo de aprendizagem desses sujeitos. Victor (2010) esclarece sobre a obrigatoriedade em se fazer cursos de Libras. Sobre isso, Strobel (2008, p. 102) considera que:

São raros os professores habilitados para trabalhar com os alunos surdos em sala de aula. Na maioria dos cursos de Pedagogia nas universidades não tinham [sic] estas especializações para esta área somente agora salvo pelo Decreto $\mathrm{n}^{\mathrm{o}} 5.626$, de 22 de dezembro de 2005, que dá obrigatoriedade de abertura de cursos de Libras nestes cursos, as coisas podem melhorar.

Acrescente-se a este fato a questão levantada por Medeiros (2011) sobre a falta de preparo dos professores de inglês no que se refere ao ensino para alunos surdos. A autora sugere que se priorize a qualificação dos professores para a eventualidade de precisarem lidar com esses contextos diferentes.

No que se refere ao papel do professor no processo de ensino, Victor (2010, p. 88) cita Vygotsky (2003) e Geraldi (2004) quando esses autores relatam a importância 
do professor e a valorização do "conhecimento construído pela experiência pessoal, concreta e cotidiana dos alunos, pois somente através desse conhecimento eles, ouvintes ou surdos, serão capazes de construir novos conceitos científicos”. Para isso, Victor afirma ser preciso que os professores ultrapassem barreiras linguísticas e utilizem diferentes metodologias para comunicação com os alunos surdos na sala de aula.

Gesser (2010) refere-se às características do material destinado ao aluno surdo, especificando que deve despertar seu interesse visual, para que entendam claramente a explicação. Como exemplo, o uso de recursos como datashow, gravuras e livros com imagens para que possam perceber com facilidade e a aprendizagem se desenvolva com qualidade.

Além disso, no processo de aprendizagem do inglês, os alunos surdos precisam conhecer a estrutura gramatical a partir de textos, com foco no que é visual, pois assim eles poderão compreender com mais clareza a estrutura dessa língua estrangeira.

Diante disso, supõe-se que a inclusão de alunos Surdos carece de um ambiente apropriado, com recursos visuais e professores preparados para o desenvolvimento de aulas com base em metodologias que atendam todos os alunos em suas peculiaridades educacionais, como prevê o Decreto 5.626/2005 (GONÇALVES e FESTA, 2013, p. 10).

Como metodologia de ensino, os conteúdos do inglês para os surdos devem ter como foco a modalidade escrita, da mesma forma que é o ensino do português. No entanto, na escola não há adaptação de material didático e, muito menos, livros para os alunos surdos. Quanto aos conteúdos, Ubá et al. (2008, p. 1631) sugerem que essa é uma oportunidade de:

(...) aprender a língua inglesa em sua modalidade escrita, partindo do contato/consumo de diferentes gêneros textuais, pelos quais os professores de língua inglesa possam introduzir conteúdos básicos dessa língua, aplicar algumas estratégias de leitura e mediar a interpretação textual.

Os professores de língua inglesa podem também usar com os alunos surdos estratégias com foco na leitura e na interpretação textual, por meio de muita prática com exercícios que os auxiliem no desenvolvimento de sua capacidade cognitiva (SILVA, 2005, p. 60). Também é importante que os professores conheçam autores como Quadros (1997) e Skliar (1997), para melhorar o processo de ensino e de 
aprendizagem dos surdos, a partir do conhecimento do processo de aquisição de linguagem por esses indivíduos. Essencial também é se considerar a educação bilíngue nesse contexto linguístico, ou seja, a sala de aula com o uso da Libras, que é, em geral, a primeira língua (L1) do surdo, em uma proposta contrastiva. Nesse ambiente, de acordo com Sobroza (2008, p. 2), “o professor pode desenvolver seu planejamento de forma que o aluno tenha que utilizar a língua alvo para pedir informações que realmente não tenha, que necessita opinar sobre assuntos diversos, realizar queixas e questionamentos".

Silva (2005) confirma que o uso da L1 no processo de ensino e de aprendizagem da LE faz com que o estudante surdo se aproprie melhor dos conteúdos e evolua em sua aprendizagem. Dessa forma, é imprescindível no processo de ensino e de aprendizagem do inglês pelo surdo que o professor saiba Libras e que utilize metodologias que considerem a especificidade linguística e cultural desse estudante.

\section{Metodologia}

A metodologia empregada neste trabalho é qualitativa e foi realizada por meio de uma pesquisa de campo na Escola Bilíngue Libras e Português Escrito de Taguatinga, localizada no Distrito Federal (DF), a partir da observação de aulas de língua inglesa e da coleta de questionários e entrevistas com professores e alunos surdos dessa instituição de ensino. Tais instrumentos de pesquisa tinham como objetivo investigar as concepções de ensino e de aprendizagem do inglês como língua estrangeira.

A coleta de dados ocorreu durante o mês de agosto do ano de 2015, em duas turmas, sendo uma do Ensino Fundamental e a outra do Ensino Médio. Inaugurada no mês de julho de, essa instituição é a primeira escola bilíngue Libras/Português do DF, onde a Libras é a língua de instrução e o Português é trabalhado numa perspectiva de segunda língua. A observação das aulas tinha como propósito identificar aspectos do processo de ensino e de aprendizagem, tais como: interação entre professor e aluno, análise do material didático utilizado e da organização da aula em si.

A entrevista com os estudantes surdos foi realizada em Libras, por meio de gravação em vídeo, para verificar se eles gostavam de aprender inglês e, dentre outras

questões, se o material didático facilitava a compreensão das explicações fornecidas 
pela professora. O questionário, por sua vez, foi aplicado às professoras no intuito de investigar as estratégias utilizadas no ensino do inglês como língua estrangeira para estudantes surdos. O Quadro 1 apresenta o perfil das quatro estudantes convidadas para participarem da pesquisa. Na primeira coluna, referente à identificação das participantes, foram usados nomes fictícios. Na terceira coluna, intitulada "Grau de Surdez", usamos a classificação encontrada no Programa de capacitação de recursos humanos do Ensino Fundamental: deficiência auditiva (BRASIL, 1997), que considera normal um nível de audição situado entre 0 a 16 dB e entre 250 a 4000 Hz. Acima de 16 $\mathrm{dB}$, considera-se perda auditiva. Os graus de surdez estão classificados em "leve", com perda de audição entre 16 a $40 \mathrm{~dB}$, "moderada", de 41 a $55 \mathrm{~dB}$, “moderada severa", de 56 a $70 \mathrm{~dB}$, "severa", de 71 a $90 \mathrm{~dB}$, e "profunda", quando acima de $90 \mathrm{~dB}$. Três das estudantes tornaram-se surdas na primeira infância, enquanto em Thamara a surdez é congênita. Portanto, apresentam grau de surdez leve e profundo.

Quadro 1. Perfil das estudantes

\begin{tabular}{|c|c|c|c|c|}
\hline Nome & Idade & Grau de surdez & $\begin{array}{c}\text { Surgimento da } \\
\text { surdez }\end{array}$ & $\begin{array}{c}\text { Aprendizado da } \\
\text { libras }\end{array}$ \\
\hline Gabriela & 17 anos & profundo & 3 anos & 8 anos \\
\hline Joana & 18 anos & leve & 5 anos & 6 anos \\
\hline Aline & 23 anos & leve & 3 anos & 15 anos \\
\hline Thamara & 25 anos & profundo & congênita & 3 anos \\
\hline
\end{tabular}

Fonte: as autoras

Neste trabalho as professoras foram identificadas como Maria e Eliana. A primeira, Maria, tem 46 anos, é formada em Letras Português-Inglês e trabalha como docente há 18 anos. Ela nos relata que sabe o básico da língua de sinais e que o seu primeiro contato com a comunidade e cultura surdas ocorreu há mais 10 anos em uma escola com alunos da Educação de Jovens e Adultos (EJA). Ela ensina inglês para as turmas de $7^{\circ}$ ano do Ensino Fundamental e para turmas de $1^{\circ}$ e $2^{\circ}$ anos do Ensino Médio. Também ministra aulas no turno noturno na escola Bilíngue. 
A professora Eliana tem 54 anos e é formada em Letras-Inglês. Trabalha na escola bilíngue há cerca de um ano e meio, e conta que o seu primeiro contato com comunidade surda foi na faculdade, na disciplina de Libras. Eliana trabalha com turmas de $6^{\circ}$ e $8^{\circ}$ anos do Ensino Fundamental e do $3^{\circ}$ ano do Ensino Médio, com o auxílio de uma intérprete.

\section{O ensino de inglês para surdos em uma Escola Bilíngue}

A observação das aulas ocorreu duas vezes por semana na turma de cada professora, por todo o mês de agosto de 2015, em salas de aulas com quatro a seis estudantes surdos. Observamos que, na escola bilíngue, não havia livros de inglês específicos para os alunos surdos, fornecidos pelo Ministério da Educação. Diante disso, as professoras desenvolviam o material didático que usavam em sala de aula. A escola também não possuía um laboratório de línguas, como sugerido por Silva (2005), o que certamente melhoraria a qualidade do ensino de inglês para os alunos surdos.

As aulas da professora Maria ocorreram nas segundas e terças-feiras, em turmas do $1^{\circ}, 2^{\circ}$ e $3^{\circ}$ anos do Ensino Médio. Como a professora domina a Libras, não há necessidade da presença de intérprete nesse ambiente, como sugere Silva (2005). Os conteúdos ministrados eram o verbo to be (ser/estar) e os pronomes pessoais (I, you, he, she, it, we, they). Em seguida, os alunos surdos fizeram uma atividade de fixação e depois traduziram o que estudaram para o português.

Em outra aula, a professora apresentou um texto e propôs algumas atividades. Os alunos precisavam traduzir para o português e sinalizar todas as palavras das frases estudadas. As palavras desconhecidas pelos estudantes deveriam ser procuradas no dicionário. Essa atividade incentivava os alunos a terem autonomia e reforçava a importância da pesquisa no dicionário.

A professora apresentou a escrita do inglês e comparou a estrutura dessa LE com a gramática da Libras. Nessas atividades, a professora Maria aplica a orientação de Silva (2005) e Sobroza (2008) sobre a utilização da Libras, que é a L1 dos alunos surdos, utilizando-a nas explicações e reflexões do conteúdo. Além disso, havia imagens em todos os conteúdos, o que facilitava a compreensão do assunto pelos alunos surdos, que faziam as atividades sem dificuldades. Essa situação corrobora as 
discussões de Gesser (2010) sobre a importância do uso de recursos visuais no ensino de línguas para surdos.

Outro aspecto positivo nas aulas da professora Maria é o uso de diferentes estratégias de ensino, considerando os variados estilos de aprendizagem e de proficiência no inglês de cada aluno surdo. Caso a professora percebesse, ao apresentar o conteúdo, que alguns estudantes compreendiam com mais facilidade, ela propunha que ajudassem aos que tinham mais dificuldade, o que gerava interação entre os alunos.

Em outra aula, a professora solicitou que seus alunos fizessem, em duplas, uma atividade na sala de informática. Os alunos deveriam fazer uma pesquisa e traduzir um pequeno texto no site do google tradutor do inglês para o português. Outra atividade aplicada foi sobre um pequeno texto em inglês, sobre a preparação para o vestibular. Os estudantes deveriam traduzi-lo para o português.

De modo geral, percebemos nas aulas da professora Maria que o processo de ensino e aprendizagem ocorre sem muitas dificuldades, pois a docente domina a língua de sinais e conhece o processo de aprendizagem de línguas pelo surdo, como sugerem os autores Quadros (1997), Skiliar (1997), Lacerda (1996). A professora conhece o universo cultural do surdo e isso pode ser observado em sua metodologia de ensino.

A professora explicou o uso do pronome demonstrativo "this", equivalente ao termo "isso" em português e, em seguida, apresentou o significado de "that", apontando um lápis sobre a mesa e dizendo que o termo correspondia a "lá" ou "aquilo" em português. Em seguida, passou ao plural, dizendo que os pronomes "these" e "those", eram usados para indicar a presença de "muitos lápis", considerando-se sempre a distância dos lápis em relação à pessoa.

A docente também explicou o uso dos artigos a (um/uma diante de palavras que começam com consoantes) e an (um/uma diante de palavras que começam com vogais). Os alunos surdos tiveram dificuldades de entender claramente esse conteúdo e pediram à professora para repetir a explicação. Nesse dia, o intérprete não estava presente e como a professora sabia muito pouco de Libras, os alunos surdos não se interessaram pela aula de inglês, por causa da falha na comunicação.

A professora Eliana entregava sempre as mesmas atividades de gramática para os alunos surdos fazerem nas turmas do $6^{\circ}, 8^{\circ}$ e $9^{\circ}$ anos. Nas turmas do $6^{\circ}$ ano, 
verificou-se que a docente usava metodologia diferente para cada uma das turmas. Como em uma turma os alunos aprendiam mais rapidamente e, na outra, além da surdez, havia a ocorrência diferentes deficiências, a professora usava estratégias lúdicas, para explicar o assunto, com o uso de jogos e imagens, trabalhando um conteúdo mais básico.

Em relação à professora Eliana, observou-se a necessidade de a docente se aprofundar no conhecimento da Libras e da cultura surda, para conseguir estimular o aprendizado de inglês de todos os estudantes surdos. Também seria importante o uso mais intensivo de materiais didáticos visuais, pois embora essa professora use algumas estratégias visuais, não o faz com a desejável frequência. A seguir, tem-se a análise sobre as entrevistas e os questionátios aplicados aos estudantes e às professoras de inglês da escola.

Todas as entrevistas aplicadas às quatro estudantes surdas foram em Libras. As alunas expressaram suas opiniões de forma autônoma e relataram sobre a aprendizagem do inglês como língua estrangeira na escola bilíngue. A transcrição das respostas das alunas participantes para o português foi feita pelas próprias pesquisadoras.

Indagadas sobre se gostavam das aulas de inglês, as alunas responderam: "Mais ou menos" (Joana e Gabriela); "Gosto" (Aline e Thamara). Percebe-se que as estudantes gostam das aulas de inglês, especialmente Aline e a Thamara. Uma possível explicação para o médio interesse das outras duas alunas pode estar relacionada à segunda pergunta: se as estudantes achavam fácil ou difícil aprender inglês. As respostas foram: "Difícil, porque não consigo aprender, tem a barreira, porque acho inglês e português muito diferente" (Joana); "Difícil, porque não consigo aprender e acho inglês e português bem diferentes" (Gabriela); "A professora ouvinte tem o apoio da intérprete para a explicação. Então, eu presto atenção e entendo. É fácil” (Aline); “Acho difícil, não entendo" (Thamara).

De modo geral, as estudantes afirmaram sentir dificuldades com a metodologia de ensino utilizada. Joana, Thamara e Gabriela relataram que não entendiam claramente a explicação da professora, enquanto Aline demonstrou ter capacidade de compreender a aula, apesar do pouco conhecimento que a professora tina de Libras, pois havia o apoio da intérprete. Entretanto, observa-se por parte da professora falta de conhecimento de metodologia de ensino para alunos surdos, o que contraria a visão 
de Silva (2005) e Gesser (2010), sobre a necessidade de uma metodologia mais visual e que considere a aspectos da cultura surda.

$\mathrm{Na}$ terceira pergunta, questionava-se o quanto as estudantes surdas entendiam claramente as explicações da professora de inglês, foram assim respondidas: "Mais ou menos" (Joana); "Não... depende, porque a professora pula e falta explicação certa em inglês, não entendo nada" (Gabriela); "Fácil" (Aline); "Sim, é fácil entender." (Thamara). Duas alunas, portanto, responderam que entendiam bem a explicação da professora, enquanto as outras duas disseram ter dificuldades. Dessa forma, os professores precisam observar seus alunos e propor estratégias diferenciadas para melhor desenvolvimento da aprendizagem desse grupo.

$\mathrm{Na}$ última pergunta, sobre se as estudantes gostavam do material didático utilizado pela professora, as alunas assim responderam: "Sim. Aprendo melhor, mas ainda acho difícil aprender" (Joana); "Não, porque a professora é novata” (Gabriela); “A professora usa Datashow, uma forma visual. Também usa jogo da memória, em que procuro a palavra cadeira em inglês, por exemplo, e encontro a imagem da cadeira (Aline); “Tem sim imagem” (Thamara).

Na escola há uma série de recursos e materiais didáticos visuais, que são usados pela professora Maria. As estudantes Joana, Aline e Thamara gostam do material que a professora utiliza, mas a aluna Gabriela respondeu que não gosta do material da professora Eliana, pois ela é uma professora novata. Como apresentamos anteriormente, Gesser (2010) chama a atenção dos professores para usarem materiais didáticos visuais no ensino para surdos. As respostas das estudantes nos colocam diante da necessidade de se utilizar uma metodologia que valorize mais os aspectos visuais.

As professoras Maria e Eliana também responderam a um questionário sobre aspectos do processo de ensino do inglês como LE para estudantes surdos. A primeira questão se refere ao tempo de experiência como professora. Maria tem 18 anos de profissão e Eliana, um ano e meio. Esse fator, de tempo de experiência, pode estar relacionado ao uso de diferentes estratégias de ensino para os alunos surdos.

$\mathrm{Na}$ segunda pergunta, questionava-se se era importante saber Libras para ensinar inglês a surdos. Maria respondeu que sim, e completou: "Para que haja interação entre professor e alunos, para que o professor possa explicar e tirar dúvidas dos alunos em Libras". Eliana respondeu: "Com certeza, porque para os surdos a 
primeira língua é a Libras". As duas professoras concordaram que é necessário saber Libras para que seja possível interagir com os estudantes e também para a explicação dos conteúdos, confirmando Strobel (2008), que indica a obrigatoriedade de todos os professores fazerem curso de Libras na graduação, de acordo com o exposto pelo Decreto $n^{\circ} 5626 / 2005$.

$\mathrm{Na}$ terceira questão procurou-se averiguar qual foi o primeiro contato das professoras com a comunidade surda. Maria respondeu que, no seu caso, ocorrera há tempo, em uma escola na Educação de Jovens e Adultos (EJA) com estudantes surdos. Eliana relatou que o seu primeiro contato com surdos se deu na faculdade, quando cursou a disciplina Libras, e em um curso de Libras por imersão.

A quarta pergunta questionava se na primeira experiência como professoras de surdos elas já dominavam a Libras. Maria respondeu que não. "Era necessário recebêlos em minha sala e promover sua inclusão junto aos ouvintes. Como eu não sabia Libras, vinha um aluno surdo, mas que ouvia um pouco, para ser o intérprete". Eliana respondeu que sua primeira experiência como professora de Libras era naquela escola bilíngue, onde ela trabalhava. Sobre se dominava a Libras, sua resposta foi: "Ainda não”. Ambas as professoras, portanto, não dominavam a Libras em suas primeiras experiências como professoras de surdos. Em relação ao aprendizado do inglês pelos alunos surdos, Maria afirma: "eles gostam e aprendem, sim, porque hoje sei Libras para me comunicar com eles. Aprendem de acordo com suas possibilidades e limitações. Os que falam, gostam de pronunciar, os que sabem mais ajudam os que sabem menos”. Eliana afirma que a falta do domínio da língua torna a comunicação um pouco difícil, e completa, dizendo que usa alguns recursos visuais, "processo que torna a aula mais dinâmica".

A professora Maria, por saber Libras, tem boa comunicação com os estudantes e observa que eles gostam de aprender inglês, possivelmente, como sugere Gesser (2010), por causa da metodologia adequada que utiliza. A professora Eliana identifica certo grau de dificuldade de aprendizagem dos estudantes e, por isso, utiliza recursos visuais. As duas professoras afirmam que é necessário usar uma metodologia diferenciada e mais visual no ensino de inglês para surdos, tema da pergunta de número seis. Sobre a opção por uma metodologia mais adequada, Maria responde: "Sim, porque é preciso dar prioridade e enfatizar leitura e escrita. Oferecer bastante material pronto para execução de atividades e usar a Libras para comunicação, 
explicação e tirar dúvidas”. Eliana também concorda com uso de uma metodologia diferenciada: "Com certeza, porque eles são muito visuais".

A sétima pergunta, se as professoras usam materiais visuais em suas aulas, foi respondida afirmativamente por Maria: "Sim. Precisa ser material com recursos visuais, mais básicos e práticos. Exercícios com repetições para treinar bastante a parte escrita. Podemos até usar o mesmo material que se usa com o aluno ouvinte, porém precisamos explicar mais e/ou exemplificar mais para que o surdo compreenda. E tem aluno surdo que supera (é melhor) que o aluno ouvinte. Eles têm bastante interesse pelos estudos." Eliana também repondeu de forma afirmativa: "Sim quando eu acho, eu uso muitos materiais visuais, palavras cruzadas, caça-palavras, jogos, vídeos etc."

As professoras percebem que o uso de recursos visuais melhora o aprendizado do aluno surdo. Maria afirma a importância desses recursos para melhora "a visualização, o entendimento e a percepção”. Eliana também aprova o uso de recursos visuais e completa: "É muito necessário o uso de recursos visuais, ele assim muito mais ajuda muito eles, e também aprendem mais. O aprendizado é bem melhor".

Sobre a convivência de três línguas (Libras, Português e Inglês) no processo de ensino aos alunos surdos no ambiente escolar, Maria afirma que "o uso da língua portuguesa é mais difícil para os alunos surdos. Eles gostam de aprender inglês também fazem traduções em português, mas para alguns alunos surdos, o português é pouco conhecido e não tem muito significado. Assim com alguns conhecem poucas Libras também". Sobre o mesmo tema, Eliana afirma achar essaconvivência "um pouco difícil”.

Ao respoderem a pergunta sobre qual o melhor ambiente de aprendizagem do inglês pelo surdo, se a Escola Bilíngue Libras/Português ou a Escola Inclusiva, Maria afirmou ser "a escola bilíngue porque o foco de ensino é para os alunos surdos, enquanto que na escola inclusiva o foco é para os alunos ouvintes, ficando os surdos às vezes, excluídos do processo de aprendizagem, principalmente por que estão em menor número nas escolas inclusivas". Eliana respondeu que "sem sombra de dúvida, o melhor lugar era na escola Bilíngue Libras/Língua Portuguesa, onde os surdos podem interagir entre si”. E completa: "Não concordo com inclusão, pois ficam isolados, não têm professores capacitados e, quando há um bom professor, como ele vai poder ajudar um único aluno quando há tantos na sala de aula?" 
Silva (2005) defende que o ensino ideal para o surdo é em uma sala de aula exclusiva para esses estudantes, devido à sua especificidade linguística, como ocorre nas escolas bilíngues. Sobre as metodologias de ensino de inglês como LE em outros países, as professoras afirmam que desconhecem o assunto, talvez por causa da pouca divulgação dessas experiências no meio docente. Quanto à preferência pela língua escrita, a professora Maria observou que, entre o inglês e o português, os estudantes mostram preferência pelo aprendizado do inglês: "Percebo mais interesse dos alunos, mas isso depende também das professoras, de sua interação com os alunos e da metodologia que usam". Para a professora Eliana, as dificuldades, em inglês e português, são as mesmas.

Para melhorar o ensino de inglês para surdos na escola, a professora Maria aponta a necessidade de terem mais materiais oferecidos pelo governo que sejam escolhidos pelos professores, e afirma, referindo-se aos livros: "Nesta escola, por exemplo, ainda não recebemos nem o material que é distribuído para outras escolas e nunca participei de escolha do material". A professora Eliana acredita que faltam professoras que saibam Libras e mais incentivo aos alunos, para que aprendam a matéria. Para as professoras, o fornecimento de materiais para o ensino aos alunos surdos, promovido pelo governo, e a qualificação dos professores no que se refere à proficiência em Libras são pontos importantes.

A última questão foi apresentada como um espaço livre para as professoras darem sugestões ou fazerem comentários sobre o tema. A professora Eliana relatou que os alunos surdos precisam ter consciência de que é importante aprender inglês, principalmente se querem fazer faculdade, pois o inglês é uma língua universal. A professora Maria não se manifestou.

Esses dados nos permitiram refletir de forma mais pontual sobre os processos de ensino e aprendizado de inglês para surdos. Os dados sugerem que o sucesso desse processo está diretamente ligado ao uso de uma metodologia bilíngue e bicultural, e evidencia que, para se realizar um bom trabalhar com surdos, é essencial o conhecimento da língua de sinais e de aspectos cultura comunidade surdas.

\section{Considerações finais}

Este artigo buscou explicitar alguns aspectos do processo de ensino e de aprendizagem do inglês por alunos surdos de uma escola bilíngue (Libras e Português), 
utilizando como metodologia a observação de aulas e a aplicação de questionários e entrevistas a estudantes e professores da escola.

Nas entrevistas, observamos que as estudantes gostam de aprender inglês, mas sentem dificuldades. Essas dificuldades mostraram ser provenientes do processo de ensino, que dificulta ao aluno o acesso aos conteúdos devido ao não domínio da Libras por parte do professor, ou ainda, pela falta de conhecimento do inglês pelo intérprete. Acrescentamos ainda a escassez de material didático próprio para esse ensino.

Observou-se que, em muitas escolas, o acesso tardio a uma metodologia que considere a cultura visual do surdo, prejudica o seu desenvolvimento escolar. $\mathrm{O}$ domínio da Libras e o conhecimento das peculiaridades da cultura surda, levou a aprofessora Maria a desenvolver estratégias de ensino adequadas. Essa "pedagogia visual" permitiu que avançasse mais nos conteúdos de sua disciplina e obtivesse maior desenvolvimento dos surdos em suas aulas. Nas turmas da professora Eliana, o avanço foi significativamente menor.

Uma educação bilíngue para os estudantes surdos, com a valorização de estratégias de ensino que utilizem, predominantemente, recursos visuais, é essencial para que os surdos se apropriem, de forma adequada, de termos e conceitos necessários para o sucesso do processo de ensino e aprendizagem do inglês como LE.

\begin{abstract}
This article aims to describe the ease and difficulties inherent to the process of teaching and learning English as an FL by deaf students in a bilingual school located in BrasíliaDF. The theoretical framework is based on discussions about the deaf subject, their language and culture, as well as on the teaching and learning process. Observations of classes, interviews and questionnaires were carried out to four deaf students and two English teachers in the observed school. The data indicate the need to use teaching methodologies that contemplate the linguistic and cultural specificities of the deaf, especially regarding the use of the Brazilian Sign Language in this process.
\end{abstract}

Keywords: Bilingual School. Teaching / Learning. English. Deaf people.

\title{
Resumen
}

Este artículo tiene el objetivo de narrar las facilidad y las dificultades propias al proceso de enseñanza y aprendizaje de inglés como LE por alumnos sordos en una escuela bilingüe, ubicada en Brasilia-DF. La base teórica se pauta en las discusiones sobre el sujeto sordo, su lengua y su cultura, así como en el proceso de enseñanza y de 
aprendizaje. Se realizaron observaciones de las clases, entrevistas y se aplicaron cuestionarios a cuatro estudiantes sordas y a dos profesoras de inglés en la escuela observada. Los datos indican la necesidad de utilizar métodos de enseñanza que contemplen las particularidades lingüísticas y culturales de los sordos, especialmente en lo que se refiere al uso de la Lengua Brasileña de Señales en este proceso.

Palabras clave: Escuela bilingüe. Enseñanza / Aprendizaje. Inglés. Personas sordas.

\section{Referências}

BRASIL. Secretaria de Educação Especial Deficiência auditiva. Org. Giuseppe Rinaldi et al. Programa de capacitação de recursos humanos do Ensino Fundamental: deficiência auditiva. Brasília: SEESP/MEC, 1997. Disponível em: http://www.dominiopublico.gov.br/download/texto/me002295.pdf Acesso em: $10 \mathrm{de}$ nov. 2015.

BRASIL. Lei no 10.436, de 24 de abril de 2002. Dispõe sobre a Língua Brasileira de Sinais - Libras e dá outras providências. Diário Oficial [da] União, Brasília, DF, 25 abr.2002. Disponível em: http://www.planalto.gov.br/ccivil_03/leis/2002/L10436.htm Acesso em: 10 out. 2015.

BRASIL. Decreto $\mathbf{n}^{\mathbf{0}} \mathbf{5 . 6 2 6}$, de 22 de dezembro de 2005. Regulamenta a Lei $\mathrm{n}^{\circ} 10.436$, de 24 de abril de 2002, que dispõe sobre a Língua Brasileira de Sinais - Libras, e o art. 18 da Lei no 10.098, de 19 de dezembro de 2000. Diário Oficial [da] União, Brasília, DF, 23 dez. 2005. Disponível em:

http://www.planalto.gov.br/ccivil_03/_ato20042006/2005/decreto/d5626.htm . Acesso em: 07 abr. 2015.

BRASIL. Lei no 9.394, de 20 de dezembro de 1996. Estabelece as diretrizes e bases da educação nacional. Disponível em: http://www.planalto.gov.br/ccivil_03/leis/19394.htm. Acesso em: 29 ago. 2015.

BRITO, L. F. Por uma gramática de línguas de sinais. Rio de Janeiro: Tempo Brasileiro: UFRJ, 2010 [1995].

CAMPELlO, A. R. S. Aspectos da visualidade na educação de surdos. Tese Programa de Pós-Graduação de Educação da Universidade Federal de Santa Catarina, 2008.

FELIPE, T. A. Libras em contexto. Rio de Janeiro: WalPrint Gráfica e Editora, 2007.

GESSER, A. Metodologia de Ensino em Libras como L2. Florianópolis: Editora UFSC, 2010. 
GONÇALVES, H. B; FESTA, P.S. Metodologia do professor no ensino de alunos surdos. Revista Eletrônica do Curso de Pedagogia das Faculdades OPET ISSN 2175-1773, dezembro 2013. Disponível em: http://www.opet.com.br/faculdade /revista-pedagogia/pdf/n6/ARTIGO-PRISCILA.pdf . Acesso em: 24 de abr. 2015.

LACERDA, C. B. F. Um pouco da história das diferentes abordagens na educação de surdos. Cad. CEDES vol.19 n. 46, Campinas: Setembro, 1998. Disponível em: http://www.scielo.br/scielo.php?script=sci_arttext\&pid=S0101-32621998000300007 Acesso em: 5 de maio de 2015.

MACHADO, P. C. A política educacional de interação/inclusão: um olhar do egresso surdo. Florianópolis: Editora UFSC, 2008.

MEDEIROS, T. G.. Concepções de professores de inglês e intérpretes diante das políticas educacionais inclusivas e a prática do ensino de inglês para alunos Surdos. Universidade Federal de Goiás, Goiânia-GO. Dissertação de Mestrado em Letras e Linguística, 2011.

QUADROS, R. M. Educação de surdos: a aquisição da linguagem. Porto Alegre: Mediação, 1997.

SKLIAR, C. B. Uma perspectiva sócio-histórica sobre a educação e a psicologia dos surdos. In: SKLIAR, C. B.. (Org.). Educação \& Exclusão. 3 ed. Porto Alegre: Mediação, 1997, v. 1, p. 105-155.

SILVA, C. M. O. O surdo na escola inclusiva aprendendo uma língua estrangeira (inglês): um desafio para professores e alunos. Dissertação de Mestrado. Universidade de Brasília: 2005.

SOBROZA, L. S. Aquisição $\mathbf{x}$ aprendizagem da língua estrangeira. 2008. Disponível em: http://jararaca.ufsm.br/websites/l\&c/download/Artigos08/Lidiane.pdf. Acesso em: 12 de nov. 2015.

STOKOE, W. Sign language structure: an outline of the visual communication systems of the american deaf. University of Buffalo Press, New York, 1960.

STROBEL, K. As imagens do outro sobre a cultura surda. Florianópolis: Editora UFSC, 2008.

UBÁ, R. C. et. al. Aprendizagem de língua estrangeira: um direito do aluno surdo. Anais do VIII Congresso Nacional de Educação: formação de professores. Curitiba, Paraná: 2008. Disponível em: www.pucpr.br/eventos/educere/educere2008/ anais/pdf/720_827.pdf Acesso em: 11 de nov. 2015.

VICTOR, C. F. S. A sala de aula inclusiva na rede pública com alunos surdos: um estudo de caso de um professor de língua. Universidade Federal de Goiás, GoiâniaGO. Dissertação de Mestrado em Letras e Linguística, 2010. 
VILHALVA, S. Mapeamento das línguas de sinais emergentes: um estudo sobre as comunidades linguísticas indígenas de Mato Grosso do Sul. Dissertação (mestrado) Universidade Federal de Santa Catarina, Centro de Comunicação e Expressão, Programa de Pós-Graduação em Linguística, Florianópolis, 2009. 